\title{
Effect of composition on the high rate dynamic behaviour of tungsten heavy alloys
}

\author{
Kesemen Latif ${ }^{1, a}$, Çalışkan N. Kaan ${ }^{1}$, Konokman H. Emrah ${ }^{1}$, and Durlu Nuri ${ }^{2}$ \\ 1 TÜBITAK SAGE, P.K. 1606261 Mamak Ankara, Turkey \\ 2 TOBB University of Economics and Technology, Department of Mechanical Engineering, 06560 Ankara, Turkey
}

\begin{abstract}
Tungsten heavy alloys are currently used as kinetic energy penetrators in military applications due to their high density and superior mechanical properties. In the literature, quasi-static properties of different tungsten heavy alloys based on $\mathrm{W}-\mathrm{Ni}-\mathrm{Cu}$ and $\mathrm{W}-\mathrm{Ni}-\mathrm{Fe}$ ternary systems are well documented and presented. However, comparison of the dynamic behaviour of these alloys in terms of the correlation between quasi-static mechanical characterization and dynamical properties is lacking. In the present study, dynamic properties of tungsten heavy alloys having different binder phase compositions $(90 \mathrm{~W}-7 \mathrm{Ni}-3 \mathrm{Cu}$ and $90 \mathrm{~W}-8 \mathrm{Ni}-2 \mathrm{Fe}$ ) at different projectile velocities were investigated. The examined and tested alloys were produced through the conventional powder metallurgy route of mixing, cold compaction and sintering. Mechanical characterization of these alloys was performed. In the ballistic tests, cylindrical tungsten heavy alloys with L/D ratio of 3 were impacted to hardened steel target at different projectile velocities. After the ballistic tests, deformation characteristics of test specimens during dynamic loading were evaluated by comparing the change of length and diameter of the specimens versus kinetic energy densities. The study concluded that $90 \mathrm{~W}-8 \mathrm{Ni}-2 \mathrm{Fe}$ alloy has better perforation characteristics than $90 \mathrm{~W}-7 \mathrm{Ni}-3 \mathrm{Cu}$ alloy.
\end{abstract}

\section{Introduction}

Perforation is a phenomena related to the characteristics of materials under dynamic conditions. Perforation characteristics of a material can be correlated to material properties such as density and strength as well as thickness of the projectile and impact velocity. There are several theories in the literature which determine and predict perforation characteristics of materials. Cylinder impact on an almost rigid surface is a very simple and useful experimental method for the material characterization under dynamic conditions. It is mostly called as Taylor impact [1] due to name of first applicant of this test. Although Hopkinson [2,3] method is widely preferred in similar studies, it is limited by the strain rate range of $10^{2}-$ $10^{4} \mathrm{~s}^{-1}$. By using Taylor method, higher strain rates can be achieved and the material behaviour in high strain rate levels can be observed.

It is known that during the impact of a Taylor cylinder, firstly elastic and plastic wave propagation occurs. With plastic wave propagation, specimen begins to deform plastically from the impact end. Its deformation depends on the impact velocity and material's strength dependency to such as strain hardening, strain rate and temperature. Hence, the shape of the specimen after the impact is governed by these material characteristics. Taylor impact projectiles are impacted to a hard wall with high speeds and very high strain rates occurs during impact process. Strain rate may reach values up to $10^{3}$ to $10^{6}$ depending on the impact velocity. Thus, high strain rate characteristic of the material is very important for the deformation of the projectile.

\footnotetext{
${ }^{a}$ Corresponding author: latif.kesemen@tubitak.gov.tr
}

Tungsten heavy alloys are two phase metal matrix composite materials which are generally manufactured by liquid phase sintering methods. The main phase is high density and high strength tungsten particles; the second phase, i.e, binder phase, is tough and ductile nickel based alloys which usually contain some iron, copper or cobalt. Tungsten based alloys characterized by high density, high strength and ductility which make these composite materials suitable for applications such as penetrators, radiation shields and balance weights [4-7]. In the manufacturing of tungsten heavy alloys, the use of Ni-Cu alloys as binder phase were first developed by Price et al. in 1938 [8]. Liquid phase sintered W-Ni$\mathrm{Cu}$ alloys, however, showed low strength and ductility, and in the 1950's, W-Ni-Fe alloys having better mechanical properties were developed due to the higher tungsten solubility in binder phase. For tungsten heavy alloy, higher tungsten solubility in binder phase leads to increases in room-temperature yield strength, tensile strength, and ductility [9]. In this study, perforation performance of two different tungsten alloys, $90 \mathrm{~W}-8 \mathrm{Ni}-2 \mathrm{Fe}$ and $90 \mathrm{~W}-7 \mathrm{Ni}-$ $3 \mathrm{Cu}$, was investigated under dynamic conditions by using Taylor impact test technique.

\section{Experimental procedure}

In this study, two tungsten based alloys namely given as $90 \mathrm{~W}-7 \mathrm{Ni}-3 \mathrm{Cu}$ and $90 \mathrm{~W}-8 \mathrm{Ni}-4 \mathrm{Fe}$ were prepared for the experiments. Proper amounts of $\mathrm{W}, \mathrm{Ni}, \mathrm{Cu}$ and $\mathrm{Fe}$ powders were weighted by a precision balance that has $+0.01 \mathrm{~g}$ accuracy (CP3200S, Sartorius, Germany) in order to give the alloy compositions. Mixing was performed in a turbula mixer (T2F, Glenn Mills, Switzerland) at a speed of $67 \mathrm{rpm}$

This is an Open Access article distributed under the terms of the Creative Commons Attribution License 4.0, which permits unrestricted use, distribution, and reproduction in any medium, provided the original work is properly cited. 


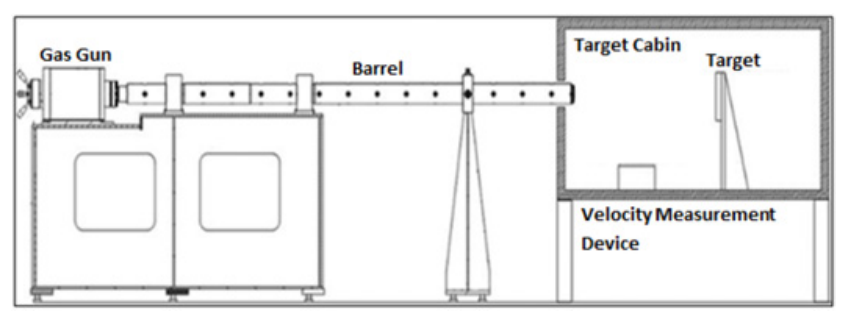

Figure 1. Set-up used in gas gun experiments.

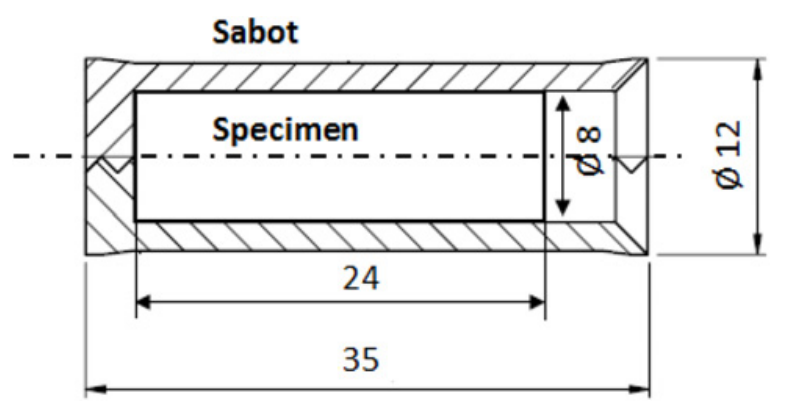

Figure 2. Sabot and specimen dimensions used in gas gun experiments.

for 45 minutes. Mixed powders were compacted by cold isostatic pressing (CIP 42260, Flow Autoclave Engineers, USA) at $310 \mathrm{MPa}$ for 15 seconds. The compacted samples of $90 \mathrm{~W}-7 \mathrm{Ni}-3 \mathrm{Cu}$ and $90 \mathrm{~W}-8 \mathrm{Ni}-2 \mathrm{Fe}$ were sintered for 30 minutes at 1430 and $1490^{\circ} \mathrm{C}$ (Linn HT-1800, Germany), respectively. After sintering, samples were heat treated at around $1100{ }^{\circ} \mathrm{C}$ under nitrogen atmosphere in order to provide intermetallic free and chemical homogeneous binder metallic phase.

Sintered alloys were characterized by evaluating their mechanical properties such as tensile strength and \% elongation. Density of the alloys was measured by Archimedes water immersion technique by using xylene with a density of $0.86 \mathrm{~g} / \mathrm{cm} 3$. The tensile test specimens were prepared as per ASTM E8 and were tested using a tensile testing machine (Zwick, Germany) with a crosshead speed of $0.5 \mathrm{~mm} / \mathrm{min}$ at room temperature. At least 3 specimens were tested and average value of the 3 specimens was reported.

The experiments were conducted by using a gas gun, a target and a velocity measurement device shown as Fig. 1. The specimens of tungsten alloys were accelerated by pressurized gas and impacted to a target in various velocities.

The gas gun used in the experiments has $12 \mathrm{~mm}$ barrel diameter. Moreover, $8 \mathrm{~mm}$ diameter specimens and $12 \mathrm{~mm}$ diameter sabots were manufactured to be accelerated along this barrel. The sabot and specimen sizes and their assembly are given in Fig. 2. The sabots are designed as two pieces to separate from the specimen before it reaches to the target.

At the exit of the gun barrel, the specimens used in the experiments reached to the final velocity measured by a velocity measurement device given in Fig. 1. Then, the specimens were impacted to a target having a close distance to the barrel exit. Target used for the specimen

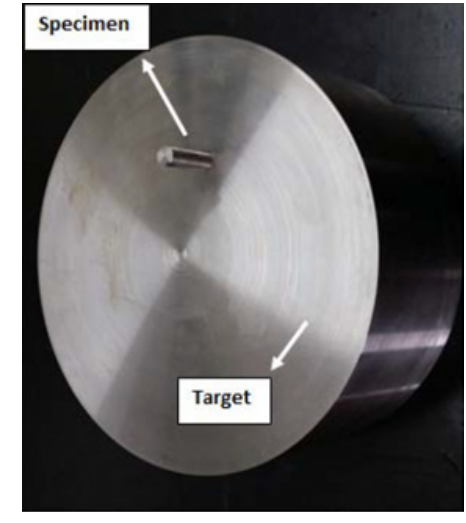

Figure 3. The target and the specimen.

Table 1. Ductility and tensile strength of liquid phase sintered tungsten alloys.

\begin{tabular}{|l|l|l|}
\hline $\begin{array}{l}\text { Alloy Composition } \\
\text { Specimen Code }\end{array}$ & $\begin{array}{l}\text { Ductility (\%) } \\
\text { Elongation) }\end{array}$ & $\begin{array}{l}\text { Ultimate Tensile } \\
\text { Strength (MPa) }\end{array}$ \\
\hline 90W-8Ni-2Fe & $29 \pm 8$ & $952 \pm 3$ \\
\hline 90W-7Ni-3Cu & $4 \pm 2$ & $729 \pm 50$ \\
\hline
\end{tabular}

impact was produced from SAE 4340 steel with a hardness of 45-50 HRc. The target was prepared large enough in order to prevent deformation due to kinetic energy of the specimens and to behave as an almost rigid body.

\section{Experimental results}

The ductility and ultimate tensile strength of the alloys are given in Table 1 . The ductility of the $90 \mathrm{~W}-8 \mathrm{Ni}-2 \mathrm{Fe}$ and $90 \mathrm{~W}-7 \mathrm{Ni}-3 \mathrm{Cu}$ alloys is approximately $29 \%$ and $4 \%$. The difference in the ductility of the alloys can be attributed to the tungsten solubility in binder matrix phase. The presence of higher tungsten solubility in the binder matrix phase led to higher tensile strength as observed in the study. Necking was observed during tensile testing for 90W-8Ni-4Fe alloys.

Taylor impact tests were conducted by two types of tungsten alloys (90W-8Ni-2Fe and $90 \mathrm{~W}-7 \mathrm{Ni}-3 \mathrm{Cu})$ under different velocities. After the specimens were impacted to the target, their diameters and lengths have been changed as shown in Fig. 4. The impact surfaces were enlarged and the total lengths were shortened due to deformation under dynamic conditions.

The final values of the diameter and length of the tested materials with different velocities were represented in Fig. 5. Three velocity levels $200 \mathrm{~m} / \mathrm{s}, 225 \mathrm{~m} / \mathrm{s}, 250 \mathrm{~m} / \mathrm{s}$ were defined to compare the results in the same conditions. Taylor tests in higher velocities cannot be achieved since both materials broke around $266 \mathrm{~m} / \mathrm{s}$ as shown in Fig. 6 . This result also showed that these two alloys, $90 \mathrm{~W}-8 \mathrm{Ni}-$ $3 \mathrm{Fe}$ and $90 \mathrm{~W}-7 \mathrm{Ni}-3 \mathrm{Cu}$, were broken into several pieces at the same limit of impact velocities.

As shown in Fig. 5, W-Ni-Cu alloy specimens had larger impact surface area than W-Ni-Fe alloys after the impact. In other words, W-Ni-Cu alloys were exposed to more deformation than the W-Ni-Fe specimens. It is observed that $\mathrm{W}-\mathrm{Ni}-\mathrm{Cu}$ alloy tungsten specimens 

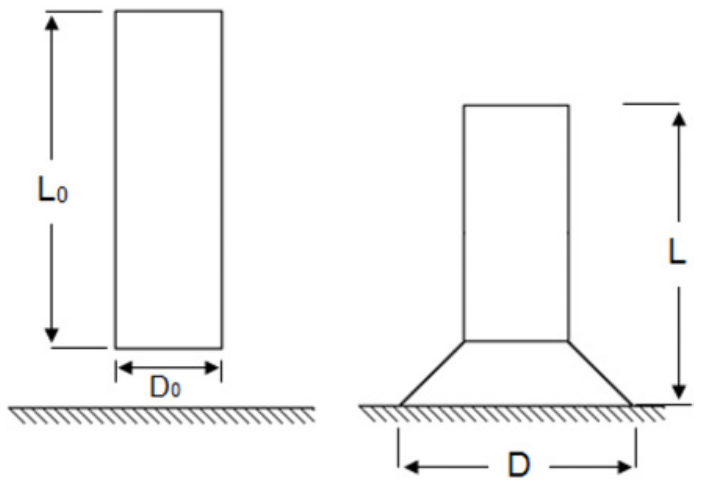

Figure 4. Taylor test scheme.
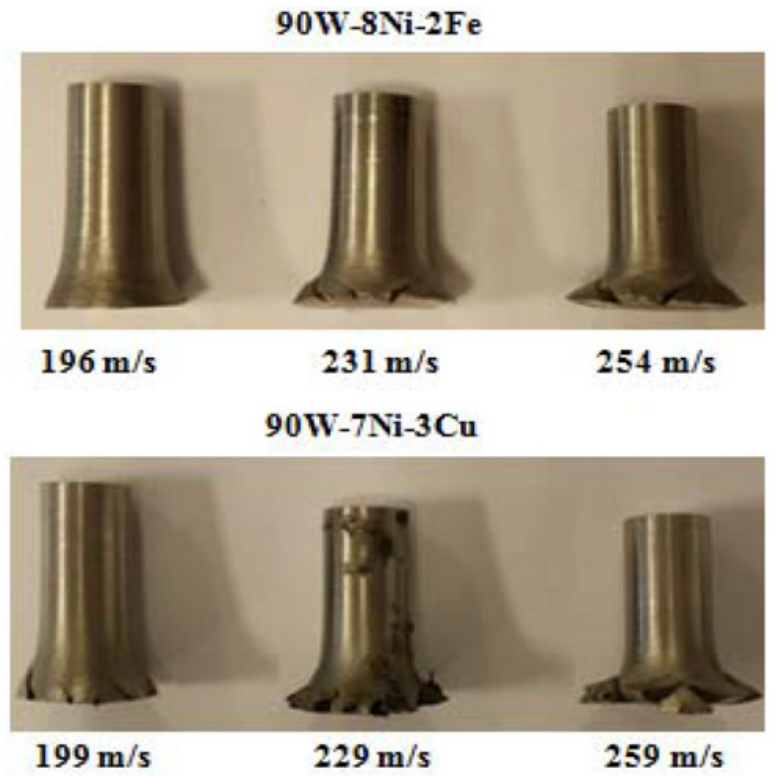

Figure 5. Final shapes of the specimens at different impact velocities.

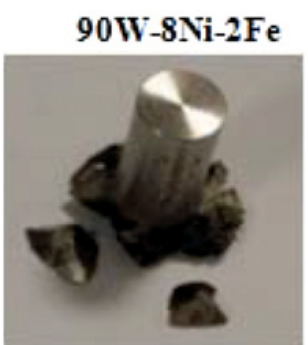

$266 \mathrm{~m} / \mathrm{s}$
$90 \mathrm{~W}-7 \mathrm{Ni}-3 \mathrm{Cu}$

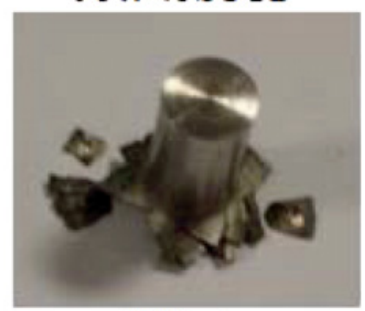

$267 \mathrm{~m} / \mathrm{s}$
Figure 6. Fracture of tungsten alloy specimens above a certain velocity.

shortens 4-7\% more and its impact end diameter becomes 15-24\% larger compared to W-Ni-Fe alloy tungsten for the same initial kinetic energies. Furthermore, it is known that deformation and the ductility inversely effects perforation and penetration of the materials. Deformation causes the larger contact face and the target applies higher resistance to penetrative material. For example, according to one of the most famous perforation equation Thor [11], larger presented area decreases in final velocity. This means that the tungsten alloy with the content of $\mathrm{W}-\mathrm{Ni}-\mathrm{Fe}$ is more
Table 2. Experiment results data.

\begin{tabular}{|l|c|c|l|}
\hline Specimen & $\begin{array}{c}\text { Velocity, V } \\
{[\mathrm{m} / \mathrm{s}]}\end{array}$ & $\begin{array}{c}\text { Diameter, D } \\
{[\mathrm{mm}]}\end{array}$ & $\begin{array}{l}\text { Length, } \\
\text { L }[\mathrm{mm}]\end{array}$ \\
\hline 90W-8Ni-2Fe & 196 & 11.8 & 20.7 \\
\hline 90W-8Ni-2Fe & 231 & 14.1 & 19.7 \\
\hline 90W-8Ni-2Fe & 254 & 15.6 & 18.8 \\
\hline 90W-7Ni-3Cu & 199 & 12.7 & 20.6 \\
\hline 90W-7Ni-3Cu & 229 & 14.9 & 19.5 \\
\hline 90W-7Ni-3Cu & 259 & 16.8 & 18.4 \\
\hline
\end{tabular}

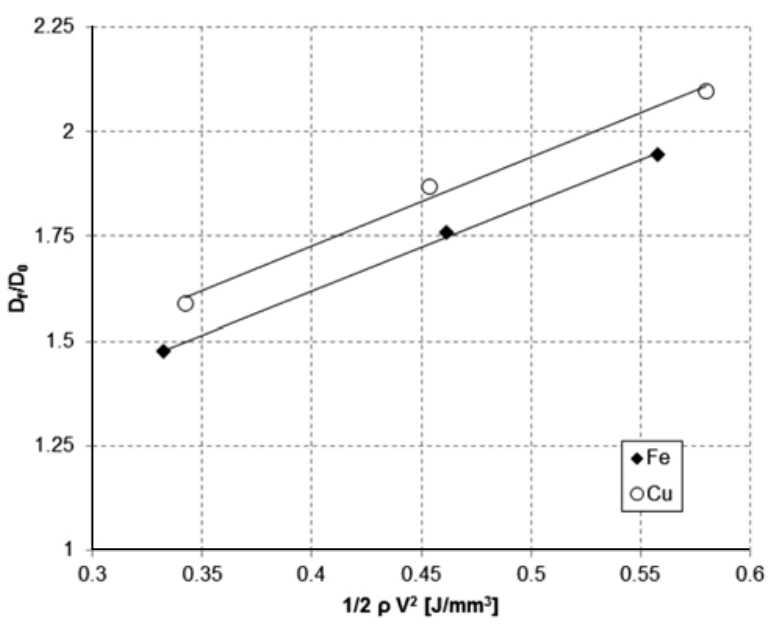

Figure 7. Diameter ratio change by initial kinetic energy.

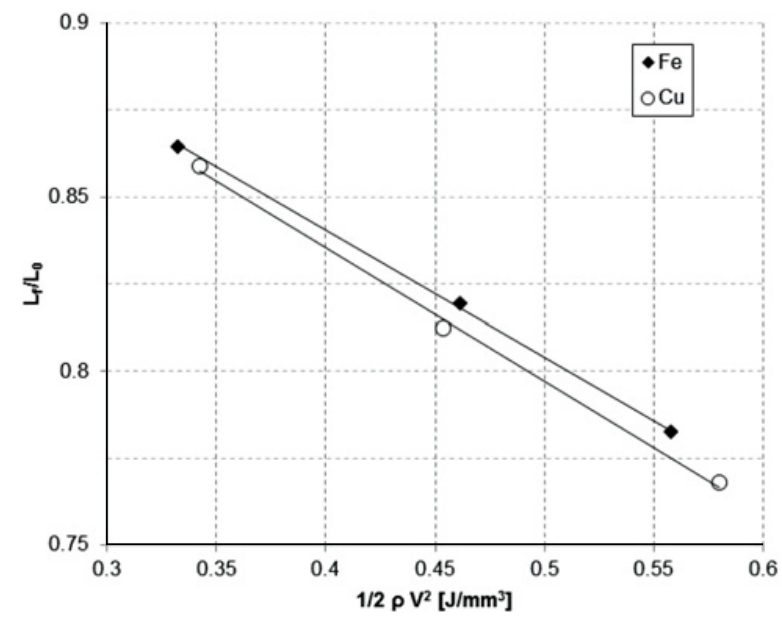

Figure 8. Length ratio change by initial kinetic energy.

effective in the perforation characteristics compared to the alloy consisting of W-Ni-Cu.

In Table 2, change in the diameter and length of specimens were given with change in the velocity of the projectile. According to these results, it can be stated that $\mathrm{W}-\mathrm{Ni}-\mathrm{Cu}$ alloy is more severely deformed than $\mathrm{W}-\mathrm{Ni}-\mathrm{Fe}$ alloy.

In order to compare the results given in Table 2, diameter and length ratios change by initial kinetic energy and initial energy were drawn graphically. All the specimens had the same volume and then the following kinetic energy formula can be used;

$$
K . E .=1 / 2\left(\rho V^{2}\right) .
$$


Since the experiments were performed at the same temperature, internal energies are assumed to be equal for all the tests. The changes in kinetic energy with diameter and length ratio variations upon impact were given in Fig. 7 and Fig. 8 respectively. As mentioned by Banarjee [10], the relation between the energy and the diameter and the relation between the energy and length ratios are linear. Our results verified the theory by Banarjee.

\section{Conclusions}

In this study, Taylor method has been utilized in order to understand the dynamic behaviour of two different types of tungsten alloys. The study showed that, 90W$8 \mathrm{Ni}-2 \mathrm{Fe}$ alloy having higher strength and ductility at quasi-static conditions has also higher strength than $90 \mathrm{~W}-7 \mathrm{Ni}-3 \mathrm{Cu}$ alloy at dynamic conditions. Furthermore, another significant result obtained by the experiments is that at the same impact velocity levels $(266 \mathrm{~m} / \mathrm{s})$, both alloys were fractured into several pieces. This indicates taht both of them have similar type of fracture behaviours under severe dynamic conditions. As a summary, by using Taylor impact test technique, $90 \mathrm{~W}-8 \mathrm{Ni}-2 \mathrm{Fe}$ alloy having a higher perforation characteristics than $90 \mathrm{~W}-7 \mathrm{Ni}-3 \mathrm{Cu}$ alloy was determined.

\section{References}

[1] Taylor G. The Use of Flat-Ended Projectiles for Determining Dynamic Yield Stress. I. Theoretical Considerations. Proceeding of the Royal Society of London. Series A, Mathematical and Physical Sciences, 194, 288-299 (1948).

[2] Hopkinson B. A Method of Measuring the Pressure Produced in the Detonation of High Explosives or by the Impact of Bullets. Phil. Trans. R. Soc. London A, 213, 437-456 (1914).
[3] Kolsky H. An Investigation of the Mechanical Properties of Materials at Very High Rates of Loading, Proc. Phys. Soc. London, B62, 676 (1949).

[4] German RM, Bourguignon LL, Rabin BH. Microstructure limitations of high tungsten content heavy alloys. J Metals; 37(8):36-9 (1985).

[5] N. K. Çalışkan, N. Durlu, Ş. Bor. Swaging of Liquid Phase Sintered 90W-7Ni-3Fe Tungsten Heavy Alloy. Int. Journal of Refractory Metals and Hard Materials, 36, 260-264 (2013).

[6] Upadhyaya A., Processing strategy for consolidating tungsten heavy alloys for ordnance applications. Mater. Chem. Phys.; 67, 101-10 (2001).

[7] N. Durlu, N. K. Çalışkan, Ş. Bor,. Effect of Swaging on Microstructure and Tensile Properties of W-NiFe Alloys, Journal of Refractory Metals and Hard Materials, 42, 126-131 (2014).

[8] G. H. S. Price, C. J. Smithells, S. V. Williams. Copper-Nickel-Tungsten Alloys: Sintered with a Liquid Phase Present. Journal of the Institute of Metals, 62, 239-264 (1938).

[9] K. E. Knipling, G. Zeman, J. S. Marte, S. M. Kelly, S. L. Kampe. Effect of Dissolved Tungsten on the Deformation of 70Ni-30Fe Alloys, Metallurgical and Materials Transactions: A. 35, 2821-2828 (2004).

[10] Project THOR, The Resistance of Various Metallic Materials to Perforation by Steel Fragments; Emprical Relationships for Fragment Residual Weight, Ballistic Analysis Lab. The Johns Hopkins Univ., Proj. THOR Technical Rept. \#47 Baltimore, MD, (1961).

[11] Biswajit Banerjee. An Evaluation of Plastic Flow Stress Models for the Simulation of HighTemperature and High-Strain-Rate Deformation of Metals. Department of Mechanical Engineering, University of Utah, $50 \mathrm{~S}$ Central Campus Dr., MEB 2110, Salt Lake City, UT 84112, USA (2005). 